Article

\title{
Preparation and Characterization of Chitosan-Agarose Composite Films
}

\author{
Zhang Hu ${ }^{1, *}$, Pengzhi Hong ${ }^{2}$, Mingneng Liao ${ }^{1}$, Songzhi Kong ${ }^{1}$, Na Huang ${ }^{1}$, Chunyan Ou ${ }^{3}$ \\ and Sidong $\mathrm{Li}^{1, *}$ \\ 1 Department of Chemistry, College of Science, Guangdong Ocean University, Zhanjiang 524088, China; \\ gdoulmn@163.com (M.L.); kongsongzhi@126.com (S.K.); 1138354521@qq.com (N.H.) \\ 2 College of Food Science and Technology, Guangdong Ocean University, Zhanjiang 524088, China; \\ hongpengzhi@126.com \\ 3 School of Pharmacy, Nanjing University of Chinese Medicine, Nanjing 210023, China; ocy545184@163.com \\ * Correspondence: huzhangqyx@126.com (Z.H.); sidongligdou@163.com (S.L.); \\ Tel: +86-759-238-3300 (Z.H.); +86-759-238-3311 (S.L.)
}

Academic Editor: Armando Silvestre

Received: 16 August 2016; Accepted: 19 September 2016; Published: 30 September 2016

\begin{abstract}
Nowadays, there is a growing interest to develop biodegradable functional composite materials for food packaging and biomedicine applications from renewable sources. Some composite films were prepared by the casting method using chitosan (CS) and agarose (AG) in different mass ratios. The composite films were analyzed for physical-chemical-mechanical properties including tensile strength (TS), elongation-at-break (EB), water vapor transmission rate (WVTR), swelling ratio, Fourier-transform infrared spectroscopy, and morphology observations. The antibacterial properties of the composite films were also evaluated. The obtained results reveal that an addition of AG in varied proportions to a CS solution leads to an enhancement of the composite film's tensile strength, elongation-at-break, and water vapor transmission rate. The composite film with an agarose mass concentration of $60 \%$ was of the highest water uptake capacity. These improvements can be explained by the chemical structures of the new composite films, which contain hydrogen bonding interactions between the chitosan and agarose as shown by Fourier-transform infrared spectroscopy (FTIR) analysis and the micro-pore structures as observed with optical microscopes and scanning electron microscopy (SEM). The antibacterial results demonstrated that the films with agarose mass concentrations ranging from $0 \%$ to $60 \%$ possessed antibacterial properties. These results indicate that these composite films, especially the composite film with an agarose mass concentration of $60 \%$, exhibit excellent potential to be used in food packaging and biomedical materials.
\end{abstract}

Keywords: chitosan; agarose; composite films; properties

\section{Introduction}

Because traditional food packaging materials cause so many environmental problems, much attention has recently been paid to biodegradable materials from renewable sources, particularly those with antibacterial properties [1,2]. Biological polymer films can be used as a protective coating to decrease the environmental impact on food and maintain food quality. Coatings and films have been fabricated with biological molecules such as polysaccharides, proteins, lipids, or combinations of the above due to their high film-forming ability.

Chitosan (CS), a naturally occurring linear cationic polysaccharide (Figure 1), has received much interest recently for its non-toxicity, biocompatibility, biodegradability, and bioactivity, and it has been extensively applied in agriculture, biotechnology, biomedicine, and the food industry [3-5]. Particularly noteworthy is that chitosan is a promising material for packaging films because of its 
film-forming properties and strong, broad-spectrum antibacterial and antifungal capabilities [6,7]. Although it has a broad spectrum of antimicrobial activity, chitosan exhibits a different kind of inhibitory efficiency against the different target organisms. Some studies have shown that chitosan generally shows stronger bactericidal effects against Gram-positive bacteria than does Gram-negative bacteria, perhaps as a consequence of the Gram-negative outer membrane barrier [8-10]. No et al. [9] reported that Staphylococcus aureus (S. aureus) is almost or completely inhibited, and Escherichia coli (E. coli) is slightly inhibited by $0.1 \%$ chitosan treatment.
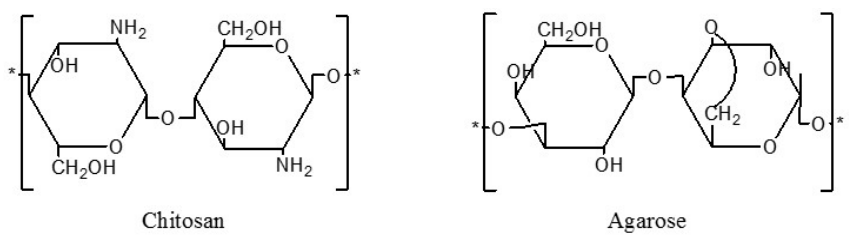

Figure 1. Chemical structures of chitosan and agarose.

Agarose (AG), which can be extracted from marine red algae, is a biocompatible linear polysaccharide (Figure 1). Owing to its especially hydrophilic and macroporous structure, agarose has a distinct ability to form a thermally reversible gel. The mechanical properties of agarose are similar to those of tissues and can be easily modulated by changing its content. Due to its renewability, biodegradability, and strong gelling power, agarose has been regarded as a strong potential candidate for use in biomaterials [11-13].

To take advantage of each individual component, material blending is an effective approach to obtain materials with ideal functional properties, and great progress has been made in the areas of food packaging and biomedical materials [14-17]. However, few studies have reported the combination of chitosan with agarose in films or coatings. In the authors' previous paper [18], chitosan-agarose composite microspheres were successfully prepared for berbamine delivery. It was found that drug adsorption and release efficacies of chitosan microspheres were improved by the introduction of agarose. In order to obtain composite films with excellent properties for food packaging or biomedical applications, the objective of the present work was to fabricate chitosan-agarose blend films and to elaborate the effect of compositions on the performance of these composite films.

\section{Results and Discussion}

Some glossy and elastic films were successfully peeled from the Teflon-coated glass dishes. They appeared to be cream-colored and did not easily break.

\subsection{Mechanical Properties}

Films that are used for packaging are generally required to withstand external stress while maintaining their integrity and barrier properties. This requires flexibility and good mechanical properties. The tensile strength (TS) of chitosan-agarose composite films with different mass ratios was measured, and the results showed that TS values of the films increased when AG was incorporated into CS films. The TS values of the films markedly increased from 2.72 to $5.31 \mathrm{MPa}$ as the AG concentration rose from $0 \%$ to $40 \%$. The tensile strength of the composite film with an agarose mass concentration of $40 \%$ was approximately double that of the chitosan film without any agarose. However, the TS values of the films slightly decreased when the mass concentration of AG increased from $60 \%$ to $80 \%$ (Figure 2a). These results might indicate that the formation of intermolecular hydrogen bonds between the $\mathrm{NH}_{2}$ - in the $\mathrm{CS}$ and the $\mathrm{OH}-$ in the AG led to the increase of the TS value of the films. As the AG concentration exceeded $40 \%$, the decrease in TS may have resulted from a phase separation between chitosan and agarose for more hydrogen bonds forming among intramolecules rather than intermolecules. These results are similar to those reported in other studies [19]. 
As seen in Figure 2b, the elongation-at-break (EB) property of the composite films was enhanced by the introduction of AG into the CS film. However, the addition of too much AG did not significantly increase the flexibility of the composite films. The composite films were superior in mechanical properties compared with the previously studied films that used chitosan alone [20]. As a consequence, the experimental techniques adopted in this work not only successfully fabricated CS-AG composite films, but also enhanced the mechanical properties of the CS-AG composite films significantly.

\subsection{Water Vapor Transmission Rate (WVTR)}

The water vapor permeability of a film in food packaging plays an important role in food deterioration, and it is closely related to the WVTR of the film. To evaluate the influence of AG on the WVTR values of the composite films, CS films with different mass concentrations of AG ranging from $0 \%$ to $80 \%$ were investigated, and the results showed that the WVTR values of the composite films increased as AG was added in greater concentrations (Figure 2c). The results could be attributed to the exceptional gel properties of agarose. A gel with three-dimensional porous network structures forms, providing a good environment for water vapor transmission, when agarose is solubilized in water.

\subsection{Swelling Test}

The results obtained for swelling ability are shown in Figure $2 \mathrm{~d}$. The data demonstrates that the chitosan films prepared without agarose $(0 \%$ AG) and with agarose $(20 \%-80 \%$ AG) were all of high water uptake capacity, but those with agarose performed better. The high water uptake capacity of the composite films could be attributed to the hydroxyl, amino, and carboxyl hydrophilic groups that exist in chitosan and agarose [21]. A different trend was observed when the swelling results were compared to the WVTR results. The chitosan film without agarose had the lowest swelling ratio, while the composite film with an agarose mass concentration of $60 \%$ showed the highest water uptake capacity. These behaviors may be explained by the different compositions and special three-dimensional structures of different films.

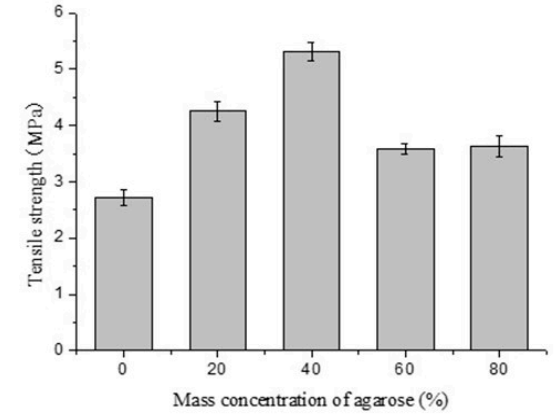

(a)

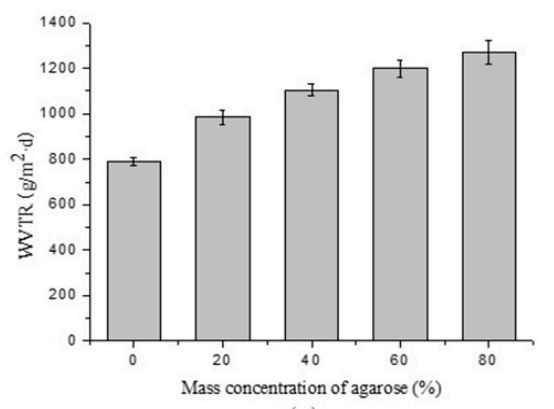

(c)

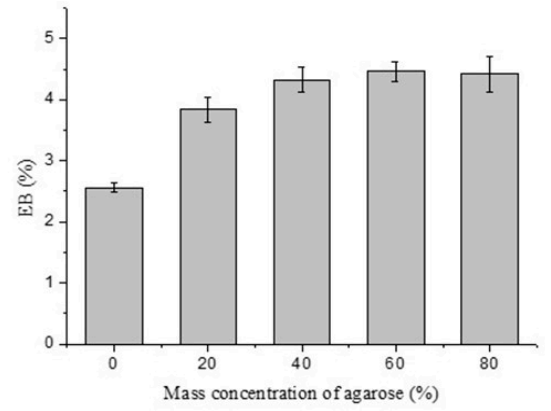

(b)

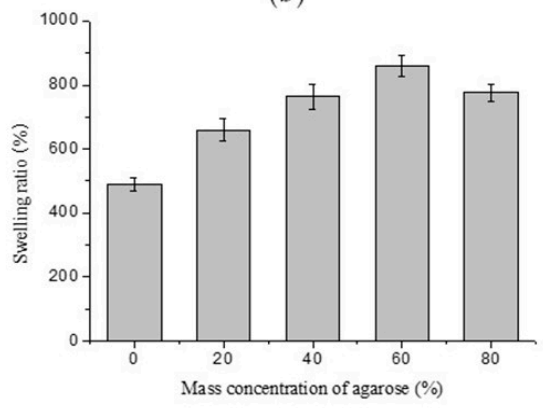

(d)

Figure 2. Effects of agarose mass ratios on (a) tensile strength; (b) elongation-at-break; (c) water vapor transmission rate; and (d) swelling ratios of the composite films. 


\subsection{Antibacterial Properties}

The antibacterial results of the composite films with different agarose contents against $S$. aureus and E. coli are listed in Table 1. As can be seen from Table 1, the antibacterial zone areas of the films without agarose were the largest. It indicated that the films composed of chitosan alone showed excellent antibacterial activity against both $S$. aureus and E. coli. It was observed that the antibacterial zone areas of the composite films with agarose mass concentrations from $20 \%$ to $60 \%$ against $S$. aureus were also relatively large. In contrast, those of the composite films against $E$. coli were dramatically decreased. This demonstrates that chitosan had stronger antibacterial effects for Gram-positive bacteria than Gram-negative bacteria. The results are consistent with previous reports [9,22], which may be due to the different chemical structures and compositions of the cell walls between S. aureus and E. coli. As for the composite films with an agarose mass concentration of $80 \%$, the antibacterial zone areas were the smallest. This proved that the composite films with $80 \%$ agarose contents only slightly inhibited the growth of $S$. aureus and $E$. coli, which is probably because the high concentration of agarose led to the aggregation of chitosan, resulting in phase separation, and then affected their antibacterial activity. The results of the antibacterial test suggested that the films with agarose mass concentrations ranging from $0 \%$ to $60 \%$ had some abilities against Gram-positive and Gram-negative bacteria, which rendered them promising for food packaging and biomedical applications.

Table 1. The antibacterial effects of the composite films with different agarose contents against $S$. aureus and E. coli.

\begin{tabular}{ccc}
\hline \multirow{2}{*}{$\begin{array}{c}\text { Films with Agarose Mass } \\
\text { Concentrations (\%) }\end{array}$} & \multicolumn{2}{c}{ Areas of the Antibacterial Zone (A, $\left.\mathbf{~ m m}^{\mathbf{2}}\right)$} \\
\cline { 2 - 3 } & S. aureus & E. coli \\
\hline 0 & $89.29 \pm 1.23$ & $83.83 \pm 0.95$ \\
20 & $78.89 \pm 0.89$ & $51.52 \pm 2.11$ \\
40 & $71.64 \pm 2.06$ & $37.38 \pm 1.58$ \\
60 & $70.56 \pm 1.55$ & $30.43 \pm 0.73$ \\
80 & $22.09 \pm 1.17$ & $13.91 \pm 1.35$ \\
\hline
\end{tabular}

\subsection{FTIR-ATR Spectroscopy}

Fourier-transform infrared spectroscopy (FTIR spectroscopy) is widely applied to identify whether a certain group or chemical bond in a molecule exists or not according to the unique energy absorption. Figure 3 shows the FTIR spectra of chitosan, agarose, and chitosan-agarose composite films with an agarose mass concentration of $60 \%$. The spectrum of chitosan film is similar to previous reports in the literature [23], and the characteristic bands of chitosan are clearly identified. The broad absorption band between 3600 and $3000 \mathrm{~cm}^{-1}$ could be attributed to the $-\mathrm{OH}$ and $-\mathrm{NH}$ stretching vibrations, the absorption bands at 1660,1592, and $1385 \mathrm{~cm}^{-1}$ are respectively ascribed to the amide I, II and III bands, and the absorption band at $1068 \mathrm{~cm}^{-1}$ is attributed to the $\mathrm{C}-\mathrm{O}$ stretching vibrations. In the spectrum for agarose film, the absorption band at $1645 \mathrm{~cm}^{-1}$ is ascribed to $\mathrm{O}-\mathrm{H}$ bending, at $1073 \mathrm{~cm}^{-1}$, attributed to the $\mathrm{C}-\mathrm{O}$ stretching vibrations. The characteristic absorption bands of 3,6-anhydrogalactose and the C-H bending vibrations of anomeric carbon appeared at 931 and $890 \mathrm{~cm}^{-1}$, respectively [24]. When different materials are mixed together, the changes in characteristic peaks of the infrared spectrum can reflect whether there are chemical interactions between them. In the spectrum of the composite film with agarose mass concentration of $60 \%$, the amide II band of chitosan shifted from 1592 to $1585 \mathrm{~cm}^{-1}$. Obviously, the shift of the amide band of chitosan to lower frequencies resulted from the addition of agarose, indicating that the presence of agarose strengthened the hydrogen bond interactions between molecules. The difference in the composition of the films could be distinguished by the spectral shifts of the amide bands because the changes in the hydrogen bond strength are related to the concentration of the substances. In addition, the absorption bands at 1068 and $1073 \mathrm{~cm}^{-1}$ associated with $\mathrm{C}-\mathrm{O}$ 
stretching joined to become one single peak, suggesting a presence of many hydrogen bonds and micro-phase separation.

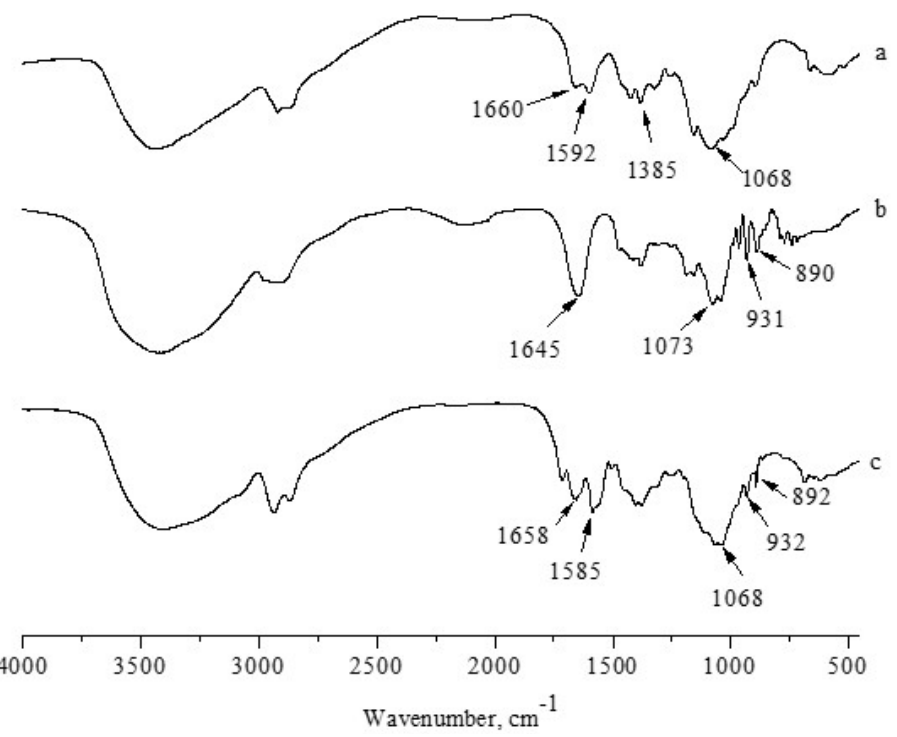

Figure 3. FTIR-ATR spectra of (a) chitosan; (b) agarose; and (c) chitosan-agarose composite film with an agarose mass concentration of $60 \%$.

\subsection{Morphology Studies}

The chitosan-agarose composite film with an agarose mass concentration of $60 \%$ was selected for morphology studies. The surface morphologies of the film were observed with a digital camera and scanning electron microscopy (SEM). The results are shown in Figure 4. In Figure 4a, which was obtained by a digital camera, the composite film is translucent, glossy and elastic. As shown in Figure $4 \mathrm{~b}$ obtained by SEM, the composite film is found to be highly porous. The pore morphology is between oval and polygonal. The size and density of the holes is not consistent. The formation of the holes is partly due to the rupture of the pore walls between the gaps left by the ice sublimation in the frozen composite film during the vacuum drying process. Micro-phase separation also occurred because of the different degrees of agglomeration in the blends. The micro-pore structures of the composite film were of great benefit to the air and moisture permeability, and cell regeneration and reproduction, evidencing this film's great development prospects in the field of biomedical materials and food packaging.

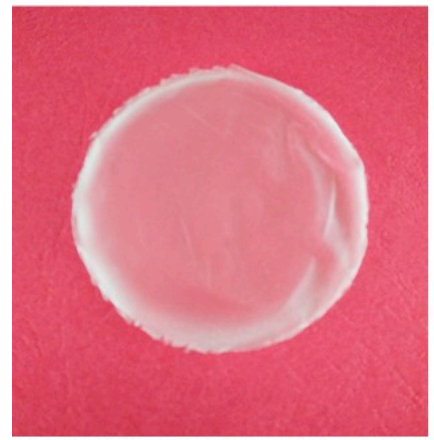

(a)

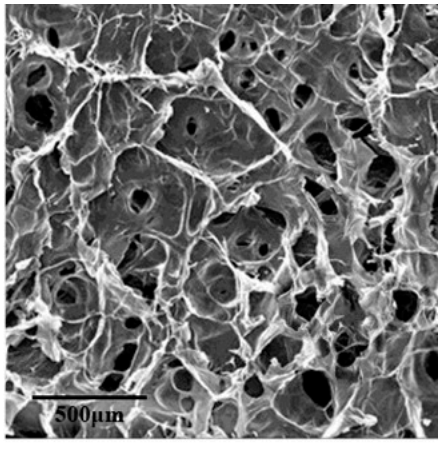

(b)

Figure 4. The (a) optical microscopy and (b) SEM micrographs of the composite film with an agarose mass concentration of $60 \%$. 


\section{Materials and Methods}

\subsection{Materials}

Chitosan (CS) with a viscosity average Mw of $1.0 \times 10^{5}$ and a degree of deacetylation of more than $85 \%$ was purchased from Greenbird Sci-Tech Development Corporation (Shanghai, China). The agarose used was provided free of cost from Taixing Bio-Technology Limited Corporation (Lianjiang, China). The acetic acid was of analytical grade.

\subsection{Film Preparation}

The films were fabricated by the casting method [25]. Solutions of chitosan $(1.5 \%, \mathrm{w} / \mathrm{v})$ were prepared by dispersing $1.5 \mathrm{~g}$ of chitosan in a $1 \%(\mathrm{v} / \mathrm{v})$ acetic acid solution and stirring for $12 \mathrm{~h}$ at room temperature. Solutions of agarose $(1.5 \%, \mathrm{w} / \mathrm{v})$ were prepared with hot distilled water stirring for $0.5 \mathrm{~h}$. Chitosan-agarose solutions were produced in mixtures of chitosan and agarose with agarose mass concentrations of $0 \%, 20 \%, 40 \%, 60 \%$, and $80 \%$ at $60{ }^{\circ} \mathrm{C}$ while stirring. The mixture solutions were poured into level Teflon-coated glass dishes and dried at $60^{\circ} \mathrm{C}$. Once the films were formed, they were transferred into a refrigerator to freeze and then freeze-dried for $8 \mathrm{~h}$. The dried films were peeled off of the dishes and placed into a desiccator with $57 \%$ relative humidity (saturated solution of sodium bromide) for use.

\subsection{Mechanical Properties}

A vernier caliper with an accuracy of $0.02 \mathrm{~mm}$ was used to measure the thickness of the films. Six different regions were measured for each film. The average thicknesses of the films at different concentrations were $0.21 \mathrm{~mm}(0 \%), 0.15 \mathrm{~mm}(20 \%), 0.14 \mathrm{~mm}(40 \%), 0.23 \mathrm{~mm}(60 \%)$, and $0.19 \mathrm{~mm}(80 \%)$. The average thickness was used to calculate the tensile strength of the films. The tensile strength (TS) and elongation-at-break (EB) were measured by a Texture Analyzer using rectangular samples $(80 \mathrm{~mm} \times 25 \mathrm{~mm})$ according to the reference method [26]. TS and EB were calculated according to Equations (1) and (2), respectively. The TS and EB tests were repeated five times for each type of film.

$$
\begin{gathered}
\mathrm{TS}=\frac{\mathrm{S}_{\mathrm{m}}}{\mathrm{L} \times \mathrm{W}} \times 100 \%, \text { and } \\
\mathrm{EB}=\frac{\mathrm{D}_{\mathrm{b}}-\mathrm{D}_{\mathrm{i}}}{\mathrm{D}_{i}} \times 100 \%,
\end{gathered}
$$

where TS is the tensile strength in MPa; $\mathrm{S}_{\mathrm{m}}$ is the maximum value of strength at break in $\mathrm{N}$; $\mathrm{L}$ and $\mathrm{W}$ are the thickness and width of the sample, respectively, in $\mathrm{mm}$; EB is the value of elongation-at-break in \%; $D_{i}$ is the original length between the two grips $(50 \mathrm{~mm})$; and $D_{b}$ is the length between the two grips right before the break of each sample in $\mathrm{mm}$.

\subsection{Water Vapor Transmission Rate (WVTR)}

WVTR $\left(\mathrm{g} \cdot \mathrm{m}^{-2} \cdot \mathrm{d}^{-1}\right)$ was gravimetrically determined using a method described by Leceta et al. [2] with a few modifications. Glass cups containing $100 \mathrm{~mL}$ of distilled water were sealed securely with the films, and their weights were recorded as $W_{b}$. The cups were placed in an environment with a humidity of $65 \%$ at room temperature. A fan in the environment at a velocity of approximately $100 \mathrm{rpm}$ was used to move the air over the surface of the films. The weights of the cups were recorded as $\mathrm{W}_{\mathrm{a}}$ after keeping for one day. WVTR $\left(\mathrm{g} \cdot \mathrm{m}^{-2} \cdot \mathrm{d}^{-1}\right)$ was calculated according to Equation (3):

$$
\text { WVTR }=\frac{\mathrm{W}_{\mathrm{b}}-\mathrm{W}_{\mathrm{a}}}{\mathrm{T} \times \mathrm{A}} \times 100 \%,
$$


where $W_{b}$ is the weight of the testing cups before timing the experiment in $g ; W_{a}$ is the weight of the testing cups after timing the experiment for one day in $\mathrm{g}$; $\mathrm{T}$ is the testing time in $\mathrm{h}$; and $\mathrm{A}$ is the testing area of the films in $\mathrm{m}^{2}$.

\subsection{Swelling Test}

The swelling test was carried out with reference to a previously reported method [27] with a few modifications as follows. The film would be weighed $\left(\mathrm{W}_{0}\right)$ first, then immersed in $100 \mathrm{~mL}$ of distilled water and placed at room temperature for $24 \mathrm{~h}$. The swelling film was taken out from the solution, and the surface water on the film was sucked out by the filter paper and subsequently weighted $\left(W_{t}\right)$. The swelling ratio (\%) was calculated according to Equation (4):

$$
\text { Swelling ratio }(\%)=\frac{\mathrm{W}_{\mathrm{t}}-\mathrm{W}_{0}}{\mathrm{~W}_{0}} \times 100 \% \text {, }
$$

where $W_{0}$ and $W_{t}$ are the weights of the films before and after swelling, respectively, in $g$.

\subsection{Antibacterial Test}

S. aureus and E. coli were the most common Gram-positive and Gram-negative bacteria, respectively. Therefore, S. aureus (ATCC-6538) and E. coli (ATCC-8739) were used to test the antibacterial property of the composite films. The samples were cut into circular films with a diameter of $10 \mathrm{~mm}$, and sterilized with ultraviolet radiation for $30 \mathrm{~min}$. The bacteria suspension $\left(0.2 \mathrm{~mL}, 10^{7} \mathrm{cfu} / \mathrm{mL}\right)$ was evenly coated on the culture dishes containing nutrient agar, and dried at room temperature for $10 \mathrm{~min}$. Then, the sterilized films were stuck on the surface of the solid medium and cultured at $37{ }^{\circ} \mathrm{C}$ for $24 \mathrm{~h}$. The areas of the inhibition zone were calculated according to Equation (5):

$$
\mathrm{A}=\frac{\pi \times\left(\mathrm{D}^{2}-\mathrm{d}^{2}\right)}{4},
$$

where $A$ is the areas of the inhibition zone in $\mathrm{mm}^{2} ; \mathrm{D}$ is the diameter of the inhibition zone in $\mathrm{mm}$; and $\mathrm{d}$ is diameter of the films in $\mathrm{mm}$.

\subsection{FTIR Analysis}

The interactions between chitosan and agarose were studied by FTIR spectroscopy (Spectrum 100, PerkinElmer, Waltham, MA, USA). The films were applied directly onto the attenuated total reflection (ATR) cell. The spectra were produced with a wave number range from 4000 to $450 \mathrm{~cm}^{-1}$ at a resolution of $4 \mathrm{~cm}^{-1}$ over 16 cumulative scans.

\subsection{Morphology Studies}

The morphology of the selected samples was observed by a DSC-TX10 digital camera (SONY Corporation, Tokyo, Japan). Scanning electron microscopy (SEM) was also carried out on a SEM JSM-6330F (JEOL Corporation, Tokyo, Japan). The sample was pre-treated by coating with an ultra-thin gold before SEM measurement.

\section{Conclusions}

Several chitosan-agarose composite films were prepared by blending chitosan and agarose together in different ratios. The physical-chemical-mechanical properties of the composite films were characterized, and the results demonstrated that the composite films, especially the composite film with an agarose mass concentration of $60 \%$, exhibited significantly improved performance in the areas of tensile strength, elongation-at-break, water vapor transmission rate, water uptake capacity, and antibacterial activity when compared with pure chitosan film. FTIR analysis, optical microscopy, and SEM characterized the chemical structures of these films, indicating hydrogen bonding interactions and 
good micro-pore structures. The composite films, especially the composite film with an agarose mass concentration of $60 \%$, exhibit excellent potential to be used in food packaging and biomedical materials.

Acknowledgments: We gratefully acknowledge the financial support by Natural Science Foundation of Guangdong Province (2016A030308009), Scientific and Technological Planning Project of Guangdong Province (2015A020216019), National Natural Science Foundation of China (51403104), and the Project of Enhancing School with Innovation of Guangdong Ocean University (2015KTSCX053, 2014KZDXM038, GDOU2013050330, and GDOU2015050253).

Author Contributions: Pengzhi Hong and Sidong Li conceived and designed the experiments; Zhang Hu and Mingneng Liao performed the experiments; Sidong Li, Songzhi Kong, and Na Huang analyzed the data; Mingneng Liao and Chunyan Ou contributed reagents/materials/analysis tools; Zhang Hu wrote the paper.

Conflicts of Interest: The authors declare no conflict of interest.

\section{References}

1. Dutta, P.K.; Tripathi, S.; Mehrotra, G.K.; Dutta, J. Perspectives for chitosan based antimicrobial films in food applications. Food Chem. 2009, 114, 1173-1182. [CrossRef]

2. Leceta, I.; Guerrero, P.; Caba, K.D.L. Functional properties of chitosan-based films. Carbohydr. Polym. 2013, 93, 339-346. [CrossRef] [PubMed]

3. Murray, C.A.; Dutcher, J.R. Effect of changes in relative humidity and temperature on ultrathin chitosan films. Biomacromolecules 2006, 7, 3460-3465. [CrossRef] [PubMed]

4. Ramya, R.; Venkatesan, J.; Kim, S.K.; Sudha, P.N. Biomedical applications of chitosan: An overview. J. Biomater. Tissue Eng. 2012, 2, 100-111. [CrossRef]

5. Ravi Kumar, M.N.V.; Muzzarelli, R.A.A.; Muzzarelli, C.; Sashiwa, H.; Domb, A.J. Chitosan chemistry and pharmaceutical perspectives. Chem. Rev. 2004, 104, 6017-6084. [CrossRef] [PubMed]

6. Agulló, E.; Rodríguez, M.S.; Ramos, V.; Albertengo, L. Present and future role of chitin and chitosan in food. Macromol. Biosci. 2003, 3, 521-530. [CrossRef]

7. Chien, P.J.; Sheu, F.; Yang, F.H. Effects of edible chitosan coating on quality and shelf life of sliced mango fruit. J. Food Eng. 2007, 78, 225-229. [CrossRef]

8. Jeon, Y.J.; Park, P.J.; Kim, S.K. Antimicrobial effect of chitooligosaccharides produced by bioreactor. Carbohydr. Polym. 2001, 44, 71-76. [CrossRef]

9. No, H.K.; Park, N.Y.; Lee, S.H.; Meyers, S.P. Antibacterial activity of chitosans and chitosan oligomers with different molecular weights. Int. J. Food Microbiol. 2002, 74, 65-72. [CrossRef]

10. Kong, M.; Chen, X.G.; Xing, K.; Park, H.J. Antimicrobial properties of chitosan and mode of action: A state of the art review. Int. J. Food Microbiol. 2010, 144, 51-63. [CrossRef] [PubMed]

11. Deszczynski, M.; Kasapis, S.; Mitchelle, J.R. Rheological investigation of the structural properties and aging effects in the agarose/co-solute mixture. Carbohydr. Polym. 2003, 53, 85-93. [CrossRef]

12. Lahooti, S.; Sefton, M.V. Effect of an immobilization matrix and capsule membrane permeability on the viability of encapsulated HEK cells. Biomaterials 2000, 21, 987-995. [CrossRef]

13. Watase, M.; Nishinari, K.; Clark, A.H.; Ross-Murphy, S.B. Differential scanning calorimetry, rheology, X-ray, and NMR of very concentrated agarose gels. Macromolecules 1989, 22, 1196-1201. [CrossRef]

14. Shih, C.M.; Shieh, Y.T.; Twu, Y.K. Preparation and characterization of cellulose/chitosan blend films. Carbohydr. Polym. 2009, 78, 169-174. [CrossRef]

15. Ke, G.; Xu, W.; Yu, W. Preparation and properties of drug-loaded chitosan-sodium alginate complex membrane. Int. J. Polym. Mater. 2010, 59, 184-191. [CrossRef]

16. Liu, F.; Qin, B.; He, L.; Song, R. Novel starch/chitosan blending membrane: Antibacterial, permeable and mechanical properties. Carbohydr. Polym. 2009, 78, 146-150. [CrossRef]

17. Da Silva, M.A.; Krause, A.C.; Kieckbush, T.G. Alginate and pectin composite films crosslinked with $\mathrm{Ca}^{2+}$ ions: Effect of the plasticizer concentration. Carbohydr. Polym. 2009, 77, 736-742. [CrossRef]

18. Hu, Z.; Li, S.; Yang, L. Preparation of berbamine loaded chitosan-agarose microspheres and in vitro release study. Polímeros 2012, 22, 422-426. [CrossRef]

19. Rao, M.S.; Kanatt, S.R.; Chawla, S.P.; Sharma, A. Chitosan and guar gum composite films: Preparation, physical, mechanical and antimicrobial properties. Carbohydr. Polym. 2010, 82, 1243-1247. [CrossRef] 
20. Martínez-Camacho, A.P.; Cortez-Rocha, M.O.; Ezquerra-Brauer, J.M.; Graciano-Verdugo, A.Z.; Rodriguez-Félix, F.; Castillo-Ortega, M.M.; Yépiz-Gómez, M.S.; Plascencia-Jatomea, M. Chitosan composite films: Thermal, structural, mechanical and antifungal properties. Carbohydr. Polym. 2010, 82, 305-315. [CrossRef]

21. Bhat, S.; Tripathi, A.; Kumar, A. Supermacroprous chitosan-agarose-gelatin cryogels: In vitro characterization and in vivo assessment for cartilage tissue engineering. J. R. Soc. Interface 2011, 8, 540-554. [CrossRef] [PubMed]

22. Elsabee, M.Z.; Abdou, E.S. Chitosan based edible films and coatings: A review. Mater. Sci. Eng. C 2013, 33, 1819-1841. [CrossRef] [PubMed]

23. Ziani, K.; Oses, J.; Coma, V.; Maté, J.I. Effect of the presence of glycerol and Tween 20 on the chemical and physical properties of films based on chitosan with different degree of deacetylation. LWT-Food Sci. Technol. 2008, 41, 2159-2165. [CrossRef]

24. Hu, Z.; Hong, P.; Li, S.; Yang, L.; Xie, J. Study on the preparation of quaternized chitosan/agarose microspheres for berbamine delivery. J. Mater. Sci. 2012, 29, 459-464.

25. Arzate-Vázquez, I.; Chanona-Pérez, J.J.; Calderón-Domínguez, G.; Terres-Rojas, E.; Garibay-Febles, V.; Martínez-Rivas, A.; Gutiérrez-López, G.F. Microstructural characterization of chitosan and alginate films by microscopy techniques and texture image analysis. Carbohydr. Polym. 2012, 87, 289-299. [CrossRef]

26. Bueno, C.Z.; Dias, A.M.A.; Cipriano de Sousa, H.J.; Braga, E.M.; Moraes, Â.M. Control of the properties of porous chitosan-alginate membranes through the addition of different proportions of Pluronic F68. Mater. Sci. Eng. C 2014, 44, 117-125. [CrossRef] [PubMed]

27. Zhang, L.; Guo, J.; Peng, X.; Jin, Y. Preparation and release behavior of carboxymethylated chitosan/alginate microspheres encapsulating bovine serum albumin. J. Appl. Polym. Sci. 2004, 92, 878-882. [CrossRef]

(C) 2016 by the authors; licensee MDPI, Basel, Switzerland. This article is an open access article distributed under the terms and conditions of the Creative Commons Attribution (CC-BY) license (http:/ / creativecommons.org/licenses/by/4.0/). 